\title{
Representações de adolescentes femininas sobre os critérios de seleção utilizados para a participação em aulas mistas de educação física ${ }^{1}$
}

\author{
Cátia Pereira Duarte* \\ Ludmila Mourão**
}

\begin{abstract}
Resumo: O presente estudo observa que as oportunidades desiguais no cotidiano da educação física escolar apontam para corporeidades generificadas que se referenciam na excelência da habilidade técnica dos movimentos, normalmente conseguida pelos meninos. Dessa forma, tornase relevante investigar as representações de escolares do $4^{\circ}$ Ciclo sobre os critérios de seleção utilizados para sua participação em aulas mistas. Através de uma perspectiva etnográfica, analisamos o discurso de doze adolescentes e observamos oitenta aulas em quatro Escolas Públicas Municipais do Rio de Janeiro. Verificamos que os critérios de seleção são definidos pela habilidade e técnica dos gestos esportivos e que os professores utilizam como referência desses gestos o padrão da habilidade masculina. Como as meninas, na sua maioria, não alcançam este perfil técnico, elas se mantêm excluídas das aulas mistas, mesmo quando o professor tem a preocupação de criar oportunidades iguais de participação.
\end{abstract}

Palavras-chave: Adolescente. Identidade de Gênero. Educação Física. Educação primária e secundária.

\section{INTRODUÇÃO}

Embora a temática de gênero seja considerada recente nos debates da Educação Física, a discussão vem crescendo entre os

${ }^{1}$ Este artigo corresponde a uma parte da Dissertação de Mestrado intitulada $O$ discurso de escolares adolescentes femininas sobre os critérios de seleção utilizados para participação em aulas mistas de educação física, defendida no Programa de Pós-Graduação em educação física e Cultura da Universidade Gama Filho, orientada por Ludmila Mourão.

* Professora do Colégio de Aplicação João XXIII, com Mestrado em Educação Física e Cultura pela Universidade Gama Filho. E-mail: catiapduarte@ig.com.br

** Professora do Curso de Graduação e Pós-graduação Stricto-Sensu da Universidade Gama Filho. E-mail: ludmila.mourão@terra.com.br 
estudiosos. Uma das inspirações das novas pesquisas na área tem sido verificar até que ponto há superação do modelo tradicional de educar o corpo em movimento, com separação de sexo. Desta forma, um dos desafios que se coloca é investigar as práticas pedagógicas da Educação Física escolar, na tentativa de compreender as formas de permanência e/ou superação do paradigma biológico, que durante décadas separou os corpos de meninos e meninas nas aulas, de acordo com as características próprias da natureza de cada sexo. Este referencial foi legitimado pelo discurso científico da área e parece ainda estar fortemente marcado nas práticas da Educação Física escolar.

Percebemos que, para construir um perfil de sucesso na educação física escolar, é preciso que alunos ${ }^{2}$ executem e treinem a técnica dos movimentos, repetindo exercícios e realizando disputas e enfrentamentos. Talvez esta seja uma das razões para que muitas meninas acreditem que seu corpo, considerado mais frágil e menos apto que o dos meninos, não esteja preparado para a prática desta disciplina, sobretudo quando seu conteúdo é esporte. Entretanto, estamos cientes de que as diferenças de habilidades entre os sexos não significam desigualdade de condições para a construção das corporeidades entre alunos.

Na década de 1990, Saraiva (2005) apontava para a necessidade de superação das condições estereotipadas relacionadas às diferenças entre os sexos nas aulas mistas de educação física, criticando o espaço restrito ocupado pelas meninas durante as aulas. Para a autora, quando meninos ocupam espaços privilegiados nas aulas de Educação física e têm maior atenção técnica dos professores do que as meninas, não se criam aulas co-educativas, apenas mistas. A autora explica que "[...] co-educação são aulas conjuntas, onde a conformação de grupos heterogênea por sexo não seria prestigiada" (SARAIVA, 2005, p.175).

Pensando nas relações sociais ainda desiguais entre homens e mulheres e identificando a extensão destas na escola, faz sentido

${ }^{2}$ Os termos alunos, professores e adolescentes são utilizados na acepção genérica.

Mavimento, Porto Alegre, v.13, n. 01, p.37-56, janeiro/abril de 2007. 
indagar acerca do que pensam as meninas do $4^{\circ}$ ciclo do Ensino Fundamental sobre os critérios de seleção utilizados para suas participações nas aulas mistas de educação física. Desdobrando esta questão, interessa-nos também verificar como elas percebem as diferenças físicas e de habilidades nas suas relações com os meninos nas aulas de Educação física. Elas vêm se sentindo excluídas e/ou desestimuladas nas aulas, na medida em que percebem que as oportunidades são iguais, mas que a exigência para a participação delas tem como referência a excelência na habilidade técnica dos movimentos?

Compreender as percepções reveladas nos discursos das alunas do $4^{\circ}$ ciclo do ensino fundamental sobre os critérios de seleção utilizados para suas participações nas aulas mistas de Educação física é a finalidade da pesquisa.

A resposta científica às questões apresentadas indicará o que pensam as adolescentes sobre os critérios de seleção utilizados para sua participação nas aulas mistas de Educação Física, e estas percepções permitirão aos professores de educação física verificar como a categoria gênero pode ser útil para ampliar as discussões sobre os comportamentos de intervenção dos profissionais e das formas de participação dos alunos nas aulas mistas de educação física. Acreditamos também que o estudo levantará algumas pistas sobre as relações de gênero na escola e na formação das corporeidades dos jovens, lugar também de inscrição e expressão, já que, cada vez mais, os jovens comunicam-se, identificam-se e diferenciam-se através de seus corpos. Caminhamos no sentido de contribuir para a construção de uma reflexão, que ainda é escassa, e que interpela professores e alunos sobre a problemática das relações de poder na corporeidade dos jovens em sua formação escolar. Estas são questões que permanecem ainda pouco exploradas no âmbito interventivo na escola e que, cada vez mais, fazem parte da vida de meninos e meninas desta geração.

A pesquisa viabiliza, mesmo que de forma indireta, a possibilidade de observar como o professor de educação física vem se envolvendo com o tema da pluralidade cultural e questões de gênero no âmbito escolar.

Movimento, Porto Alegre, v.13, n. 01, p.37-56, janeiro/abril de 2007. 


\section{CARACTERÍSTICAS METODOLÓGICAS DO ESTUDO}

Considerando que nossa intenção foi investigar as percepções das escolares que freqüentavam o $4^{\circ}$ ciclo do Ensino Fundamental sobre os critérios de seleção utilizados para suas participações nas aulas mistas de educação física, os procedimentos selecionados para a pesquisa seguiram a abordagem qualitativa. Esta abordagem, segundo Richardson (1989, p.38), “[...] além de ser uma opção do investigador, justifica-se, sobretudo, por ser uma forma adequada para entender a natureza de um fenômeno social".

Corroborando com os pressupostos citados, utilizamos alguns elementos da etnografia, na medida em que permanecemos nas escolas durante um semestre letivo, reunindo em diário de campo uma média de oitenta observações de aulas mistas de educação física, em quatro escolas Municipais no Rio de Janeiro, procurando pistas para compreender a cultura escolar nas mesmas, a partir do olhar das meninas.

De acordo com Geertz (1989, p. 15), “[...] praticar etnografia é estabelecer relações, selecionar informantes, transcrever textos, levantar genealogias, mapear campos, manter um diário [...]". Há quatro características da descrição etnográfica para realizar o trabalho de forma qualitativa: ele tem que ser interpretativo; o que interpreta será o fluxo do discurso social; a interpretação envolvida consistirá em tentar salvar o "dito" num tal discurso da sua possibilidade de extinguir-se e fixá-lo em formas pesquisáveis; além de ser microscópico.

O processo de investigação utilizou a entrevista do tipo semiestruturada como principal instrumento de coleta de dados. Após acompanhar por dois meses as aulas de educação física nas escolas escolhidas, as informantes foram entrevistadas em espaços tranquiilos perto das salas de aula e longe das quadras.

Acreditamos que a técnica da entrevista semi-estruturada seja um dos tipos de entrevista válidos para captar os sentidos contidos nas falas dos informantes, devido à possibilidade de se obter maior interação entre o entrevistador e o entrevistado, como afirmam Movimento, Porto Alegre, v.13, n. 01, p.37-56, janeiro/abril de 2007. 
Lüdke e André (1986). Com esse tipo de instrumento, o pesquisador precisa estar atento não apenas ao roteiro pré-estabelecido e às respostas verbais que vai obtendo ao longo da interação, como também deve procurar focalizar os sinais não-verbais. ${ }^{3}$

Para Orlandi (2000), a análise do discurso da linguagem não é transparente, ela tem um texto, e através do conhecimento simbólico desse texto é que se concebem as relações de sujeitos e de sentidos, bem como os efeitos dessa discursividade. As palavras não significam por si, mas pelas pessoas que as falam ou pela posição que ocupam os que as falam, numa construção de sentidos que não estaciona na interpretação, mas trabalha com seus limites e mecanismos, como parte do processo de significação. Os dizeres não são apenas mensagens a serem decodificadas, são efeitos de sentidos que são produzidos em condições determinadas e que estão, de alguma forma, presentes no modo como se diz. Como nossa sociedade é constituída por relações hierarquizadas, são relações de força sustentadas no poder desses diferentes lugares que se fazem valer. Logo, não são os sujeitos físicos nem seus lugares sociais que funcionam no discurso, mas suas imagens, que resultam das projeções. A autora lembra:

$\mathrm{Na}$ análise do discurso não menosprezamos a força que a imagem tem na constituição do dizer. $\mathrm{O}$ imaginário faz necessariamente parte do funcionamento da linguagem. Ele é eficaz. Ela não brota do nada: assenta-se no modo como as relações sociais se inscrevem na história e são regidas, em uma sociedade como a nossa, por relações de poder (ORLANDI, 2000, p.42).

\section{ADOLESCEENCIA NA ESCOLA: CONSTRUINDO IDENTIDADES E REALÇANDO DIFERENÇAS}

$\mathrm{Na}$ adolescência, as transformações físicas e hormonais estão em processo, as principais mudanças corporais (aparecimento dos

${ }^{3}$ Para a transcrição dos discursos utilizamos os seguintes sinais: // para interrupção; (...) quando a informante estava pensando;... para os gaguejos; (falas dentro do parêntese) são quando a informante estava pensando;... para os gaguejos;

Movimento, Porto Alegre, v.13, n. 01, p.37-56, janeiro/abril de 2007. 
pêlos pubianos, mudança no timbre de voz, crescimento da barba ou dos seios), que geram conflitos quando começam a se manifestar, estão se consolidando. Nas aulas de educação física, o corpo de meninas e meninos está em evidência, construindo identidades e realçando diferenças.

Entre as transformações, afirmações e conflitos que vivem os jovens adolescentes, podemos citar as crises de identidade sexual e de gênero. Nesse processo de construção de identidade, a influência da família, da escola, da religião e dos amigos, através de comportamentos singulares e/ou compartilhados, liberam e restringem as vivências do adolescente.

Considerando a compreensão de gênero de Scott (1995, p. 86) como um "[...] elemento constitutivo das relações sociais fundadas sobre as diferenças percebidas entre os sexos, e o primeiro modo de dar significado às relações de poder [...]", percebe-se que gênero é uma categoria social e histórica compreendida de formas diferentes pelas diferentes culturas.

Ao nascerem, os sujeitos já trazem determinadas características biofisiológicas que os predispõem a viver como homens e mulheres, porém, há todo um conjunto de outros determinantes - sociais, psicológicos, culturais - que podem conduzi-los a se construírem em oposição ou consonância com as características biológicas. A esse propósito, Louro (2001) lembra o equívoco de se conceder o par diferença-igualdade como um dilema, citando Joan $\operatorname{Scott}^{4}$ (1988, p.46):

Lembra que a luta primeira se centrava na reivindicação da igualdade entre as mulheres e os homens (igualdade social, política, econômica). Avançando em suas teorizações, o feminismo vai responder à "acusação" da diferença transformando-a numa afirmação, ou seja, não apenas reconhecendo mas procurando valorizar, positivamente, a diferença entre mulheres e homens. Críticos do movimento vão, então, colocar essas

${ }^{4}$ Tradução do artigo de Joan Scott intitulado Gênero: Uma categoria útil para análise histórica para o português, realizada por Christine Rufino Dabat e Maria Betânia Ávila. Recife: SOS Corpo, 1991.

Movimento, Porto Alegre, v.13, n. 01, p.37-56, janeiro/abril de 2007. 
duas proposições - igualdade ou diferença - como alternativas inconciliáveis. Afinal, dizem eles, o que querem as mulheres, o que buscam afirmar: a igualdade ou a diferença? Scott observa que esse desafio representa uma armadilha, é uma "falsa dicotomia", já que igualdade é um conceito político que supõe a diferença. [...] Na verdade, reivindica-se que sujeitos diferentes sejam considerados não como idênticos, mas como equivalentes.

Énecessário demonstrar que não são propriamente as características sexuais, mas as formas como essas características são representadas ou valorizadas, aquilo que se diz ou se pensa sobre elas que vai constituir, efetivamente, o que é feminino ou masculino em uma sociedade em um dado momento histórico.

Tentando se afirmar nesta construção de identidade de gênero, os adolescentes adotam linguagens verbais e/ou gestuais que os mantenham em um grupo social diferenciado. Porém, tais linguagens criam novos códigos (de expressões, de olhares, de palavras) que, muitas vezes, não têm pretensão masculina nem feminina, mas determinam várias formas de ser menino ou menina.

Nessa linha, muitas jovens visibilizam em seus corpos sinais de singularidades e de individualidade, como prováveis reações ao anonimato e à homogeneização. Segundo Meyer e Soares (2004, p.22), o corpo feito cenário, mapa, território de protestos e de afirmação de identidades, "[...] vem praticando, demonstrados em seus variados modos de transitar e fazer-se notar, nos espaços escolares: tatuagens, piercings, novos estilos de cortes e pinturas de cabelos, brincos, maquiagens, enfeites, pulseiras, roupas rasgadas [...]”. As roupas, os acessórios (bonés, bolsas, óculos, entre outros), as ações sobre o corpo (regimes alimentares) são definidoras de identidades. Entretanto, podemos perguntar até que ponto estes mecanismos não são novos códigos de disciplina e de controle sobre os corpos.

Mesmo considerando a multiplicidade de transformações que acontecem, diariamente, em todos os níveis e em todos os lugares, observamos que a escola organiza seu cotidiano com práticas e propósitos de fixar e modelar os corpos desde a infância. Com

Movimento, Porto Alegre, v.13, n. 01, p.37-56, janeiro/abril de 2007. 
isto, o protagonismo juvenil se mantém mais reagindo aos procedimentos "normalizadores" do sistema escolar do que transformando seus cotidianos.

A aula de educação física parece reproduzir este comportamento normalizador da escola quando favorece um trabalho com as corporeidades dos adolescentes, que ressalta nos pátios e nas quadras a competição, o rendimento, a auto-exclusão dos menos aptos, dos fracos e das frágeis (as mulheres).

\section{CONTEXTUALIZANDO E ANALISANDO OS DISCURSOS DAS ADOLESCENTES}

Após aceitação do projeto de pesquisa pela Secretaria Municipal de Educação do Rio de Janeiro, e uma vez autorizado o estudo, partimos para a seleção das escolas. Dentre as Coordenadorias Regionais de Educação (CRE) sugeridas pela própria Secretaria Municipal de Educação, optou-se pela $5^{\mathrm{a}} \mathrm{CRE}$ intencionalmente, por esta se localizar no entorno da Universidade Gama Filho, possibilitando o retorno da pesquisa para a comunidade que cerca a instituição promotora do trabalho. Dentre as 109 escolas situadas nessa região, seis escolas foram escolhidas por sorteio para participar da pesquisa: Escola Municipal França, Quintino Bocaiúva, Oswaldo Teixeira, Cardeal Arco Verde, Ministro Edgard Romero e Professor Manoel Maurício.

Feito um levantamento da organização e do funcionamento das escolas, descobrimos que duas dessas não poderiam fazer parte da pesquisa: a Escola Municipal Cardeal Arco Verde, por não realizar aulas mistas, e a Escola Municipal Professor Manoel Maurício, por não ter turma do $4^{\circ}$ ciclo. Assim, confirmamos junto à $5^{\mathrm{a}} \mathrm{CRE}$ que efetivaríamos o estudo nas quatro escolas restantes.

No decorrer das aulas, observando a forma de interação das alunas nas atividades e nos jogos e conversando informalmente com elas e com as professoras, construímos os perfis das meninas que viriam a ser entrevistadas na pesquisa: Perfil A - menina que fazia as aulas e gostava de praticar as atividades; Perfil B - menina que fazia as aulas, mas variava comportamentos de indiferença e

Movimento, Porto Alegre, v.13, n. 01, p.37-56, janeiro/abril de 2007. 
de esforço frente às atividades e Perfil $\mathrm{C}$ - menina que não participava das aulas e demonstrava insatisfação durante as aulas de educação física. Nas aulas subseqüentes, definimos as informantes de forma intencional, ficando com três alunas em cada uma das quatro escolas (uma de cada perfil), totalizando 12 meninas que frequientavam turmas do $4^{\circ}$ ciclo das escolas observadas.

Diante das observações das aulas e dos diálogos com as informantes, realizamos uma análise dos discursos sobre o que estas meninas pensavam sobre as aulas de educação física, como esta disciplina poderia funcionar no âmbito escolar, como acreditavam que os colegas as percebiam, quais eram os critérios utilizados para seleção dos times, e, por último, quais eram as oportunidades de participação de meninos e meninas nas aulas de educação física.

Analisando o discurso das meninas sobre a percepção da educação física escolar, encontramos as meninas do Perfil A privilegiando a disciplina como aquela que poderá vir a contribuir para que elas sejam atletas no futuro e, dessa forma, representam a disciplina como espaço de liberação de energia, a "educação física é boa, a gente fica sabendo vários esportes" e "a gente pode ser atleta no futuro" além de "relaxar o corpo". Verificamos uma forte diferença entre o discurso destas alunas consideradas mais hábeis em relação ao das outras, que mostram um desestímulo frente às aulas de educação física e às atividades desportivas. Entretanto, segundo Louro (2003, p.42), a opção que têm os educadores diante de um cenário de incertezas é "[...] assumir os riscos e a precariedade, admitir os paradoxos, as dúvidas, as contradições e, sem pretender lhes dar uma solução definitiva, ensaiar, em vez disso, respostas provisórias, múltiplas, localizadas". Desta forma, o professor deve, entre as mais estimuladas e as menos aptas, procurar estimular ambas e propor desafios que alterem e desequilibrem ambos os grupos no sentido de otimizar as práticas corporais nas aulas.

As meninas do Perfil B, que participam ocasionalmente das aulas, também não esquecem da funcionalidade da disciplina, porém percebem que certas exigências motoras lhes causam constrangimentos. Quando revelam que gostam das aulas "eu gosto, mas eu

Movimento, Porto Alegre, v.13, n. 01, p.37-56, janeiro/abril de 2007 
tenho vergonha de fazer isso", elas entendem a aula de educação física como um espaço de exposição dos seus corpos, tanto na perspectiva estética quanto da performance motora. Desta forma, elas vivem um conflito entre a realização das atividades e a frustração nas mesmas, pois se preocupam com o fato de não realizarem o gesto esportivo ou o movimento exigido segundo a habilidade esperada pelos colegas e, muitas vezes, por suas professoras. Nesse discurso, as diferenças de gênero estão sobre a mesa de discussão, e assim esperamos que elas se tornem foco das reflexões do professor de educação física.

Segundo Louro (2003, p.44), uma noção singular de gênero e sexualidade vem sustentando currículos e práticas em nossas escolas, e é consenso que:

$$
\begin{aligned}
& \text { [...] a instituição escolar tem obrigação de nortear } \\
& \text { suas ações por um padrão: haveria apenas um } \\
& \text { modo adequado, legítimo, normal, de mascu- } \\
& \text { linidade e de feminilidade e uma única forma sadia } \\
& \text { e normal de sexualidade, a heterossexualidade; } \\
& \text { afastar-se deste padrão significa buscar o desvio. }
\end{aligned}
$$

Sob esta égide, apenas um grupo minoritário de meninas adolescentes aparece como dominante na área do esporte na escola, as demais não se desviam do padrão escolar, participam de atividades suaves, sem contato e leves, mantendo seus corpos dóceis segundo a análise de Foucault (1997).

As alunas do Perfil $\mathrm{C}$ revelam pouco envolvimento com as aulas, por isso não entendem a funcionalidade da disciplina a não ser como um espaço de exposição de suas fraquezas e inseguranças. Elas anunciam em suas falas que os outros não lhes passavam a bola, que não eram selecionadas para jogar e que não gostavam do que vinha sendo feito nas aulas. No discurso dessas alunas, percebemos que na prática, se mantém o lugar especial e problemático das identidades "marcadas". As diferenças de gênero que são atribuídas às mulheres, sem dúvida, se expressam materialmente em seus corpos, e na concretude de suas vidas, ao mesmo tempo em que são significadas e marcadas discursivamente.

Movimento, Porto Alegre, v.13, n. 01, p.37-56, janeiro/abril de 2007. 
Quando questionadas sobre como gostariam que as aulas de educação física acontecessem, as meninas do Perfil A valorizaram os esportes como os conteúdos centrais da matéria, manifestando que os mesmos poderiam ser mais bem trabalhados, com ênfase no ensino das técnicas, muito próximo do desejo dos meninos. A fala destas meninas caracteriza a cultura hegemônica do esporte na escola, bem como sua reprodução, embora anunciem também a fragilidade no ensino dos esportes pelos professores.

Já as meninas do Perfil B percebem que os esportes não devem ser os únicos conteúdos da matéria: "a aula poderia ser mais variada em relação aos conteúdos". Essas criticam a desportivização exacerbada nas aulas de educação física, e reivindicam o ensino de outros conteúdos; indicando que muitas meninas podem estar se excluindo da participação nas aulas mistas, por vivenciarem o esporte com ênfase nas suas técnicas.

As meninas do Perfil $\mathrm{C}$ estão na linha reivindicatória das meninas do perfil anterior. Criticam os colegas dizendo que: "todos tinham que pegar na bola", indicando que o exagero da cobrança técnica prejudica os menos habilidosos. Observamos que as diferenças, traduzidas em falta de habilidade, terminam por gerar comportamentos de auto-exclusão dessas meninas.

Contudo, quando questionadas sobre o que achavam que os meninos pensavam sobre elas, as meninas do Perfil A relataram que quando jogam bem os meninos reconhecem: “[...] pelo menos no futebol, eles falaram que eu jogo bem". Porém não percebem que tais palavras mostram o sexo como definidor da competência para o jogo, que segundo Goffman (1982) é uma forma escamoteada de simular os preconceitos.

As meninas do Perfil B não se sentiam percebidas, não tinham idéia sobre o que os meninos poderiam pensar sobre elas, e comentaram: "os meninos não falam nada"; "não sei". Mas as meninas do Perfil $\mathrm{C}$ assumiram suas invisibilidades nas aulas, quando afirmaram: "[...] eles nem me observam", "não fico no meio", "fico mais no meu canto". Abreu (1990) frisa que é preciso definir o perfil dos

Movimento, Porto Alegre, v.13, n. 01, p.37-56, janeiro/abril de 2007. 
alunos e das alunas que pretendemos educar, para, então, adotar uma postura pedagógica. Desta forma, os professores deveriam aproveitar essas situações para trabalhar as diferenças de gênero e diferenças entre os perfis de cada aluno.

No item em que as meninas foram estimuladas a nos dizer o que as outras pensavam sobre elas, encontramos os três perfis sendo criticados, sem nenhuma simulação. As meninas do Perfil A se queixaram de que as colegas se incomodam com o fato de elas jogarem bem e nos diziam isso da seguinte forma: "[...] elas falam que eu jogo muito"; "elas não vão com a minha cara", nos remetendo a um sentimento de desprezo daquelas que têm menos habilidade em relação àquelas que têm mais habilidade e que mais participam das aulas de educação física. As meninas do Perfil B comentaram que as colegas, "falam, brigam, implicam, se tocar nelas [...]" e as do Perfil C, mesmo participando ocasionalmente das aulas, comentaram: "[...] elas - as meninas da aula, que jogam sempre e têm habilidade - estão sempre mais enturmadas", e ainda frisaram que sobre elas, as outras dizem - elas não jogam nada; "elas zoam tanto quanto os meninos quando a gente erra".

Entendendo o corpo como um constructo cultural, compreendendo-o situado no tempo em que vive, captamos nestas falas as expressões do corpo hábil nas aulas de educação física, sendo percebido como produtivo e produto de gestos econômicos e eficientes, atravessado por diferentes marcadores sociais, sobretudo os de habilidade motora e gênero, quem sabe jogar tem mais facilidade de se enturmar - fazer amigos -, construindo um grupo social mais amplo e menos marcado pela categoria gênero na escola. Entretanto, aquelas que não têm este domínio sofrem de bullying ${ }^{5}$ pelos meninos e meninas hábeis, que demonstram boa destreza corporal nos jogos, como afirma a adolescente do perfil $\mathrm{C}$ quando diz: "elas zoam tanto quanto os meninos [...]".

Acerca dos critérios de seleção mais utilizados por elas na hora de escolher os times nas aulas, as informantes do Perfil A, B e

${ }^{5}$ Estamos entendendo bullying, de acordo com Fante (2005), como um comportamento cruel, intrínseco nas relações interpessoais, em que os mais fortes convertem os mais frágeis em objetos de diversão e prazer, através de brincadeiras que disfarçam o propósito de maltratar e intimidar.

Mavimento, Porto Alegre, v.13, n. 01, p.37-56, janeiro/abril de 2007. 
$\mathrm{C}$ afirmaram que preferiam as meninas que sabiam jogar - "pego as garotas que sabem jogar melhor" - e em seguida escolhiam as menos habilidosas, porém mais amigas. Um fato que chamou a atenção foi o relato de que as seleções são feitas seguindo o exemplo das professoras, que sempre escolhiam o time, começando pelas meninas mais "habilidosas". Os dados confirmam Lenskyj, (1986, p.132), quando ela aponta que:

\begin{abstract}
A habilidade esportiva dificilmente se compatibiliza com a subordinação feminina tradicional da sociedade patriarcal; de fato, o esporte oferecia possibilidade de tornar igualitárias as relações entre os sexos. O esporte, ao minimizar as diferenças socialmente construídas entre os sexos, revelava o caráter tênue das bases biológicas de tais diferenças; portanto, constituía uma ameaça séria ao mito da fragilidade feminina.
\end{abstract}

Quanto às oportunidades de participação dos alunos nas aulas de educação física, as informantes do Perfil A, B e C declararam que todos tinham as mesmas oportunidades, destacando que "não jogam junto - com os meninos - porque a professora tá separando". Quando a professora valoriza as meninas mais "habilidosas" no esporte, discriminando a partir das diferenças de habilidade motora, ela desconsidera outras formas de manifestações da corporeidade das alunas nas aulas, criando barreiras entre as meninas e considerando as diferenças entre elas como negativas. Observa-se que as meninas que menos participam permanecem mais presas às ambigüidades e ambivalências sobre a prática do esporte e a feminilidade que imperam na sociedade brasileira atual. Vemos por exemplo que hoje, embora não existam mais barreiras legais à participação das mulheres em determinados esportes, o sex-typing dos esportes é prática corrente, e alguns são representados como mais 'masculinos' ou mais 'femininos' (...), Adelman (2003). Dentro desta lógica, são produzidos os discursos das alunas menos habilidosas. Percebemos que meninos e meninas, exercitando-se juntos nas aulas mistas de educação física, experimentam dificuldades em realizar atividades de forma mista, que ao longo da história se constituíram como mais adequadas à corporeidade feminina ou à

Movimento, Porto Alegre, v.13, n. 01, p.37-56, janeiro/abril de 2007. 
corporeidade masculina. Algumas informantes até comentaram que eles eram brutos mesmo, "eles têm uma força incrível". No entanto, algumas meninas comentaram que poderiam melhorar seu rendimento se treinassem juntos nas aulas (talvez quisessem falar de aulas co-educativas, já que as mistas não vinham garantindo tal espaço). Trazendo para a cena as palavras de Bourdieu (1999, p.5), verificamos que a educação física escolar organiza as suas práticas a partir de estratégias sexuadas:

[...] as estratégias e práticas determinam a construção social dos corpos e fazem deles uma realidade sexuada, depositária dos princípios de visão e de divisão sexualizantes, [...] que têm o masculino como medida de todas as coisas e a própria ordem social como imensa máquina simbólica, que ratifica a dominação masculina [...], na estruturação do espaço, do tempo e do corpo.

Quando interrogadas sobre a possibilidade das atividades e dos critérios de seleção das suas aulas respeitarem um ou outro sexo, ou até mesmo os dois, as meninas não deixaram de registrar que os critérios agradavam o sexo que detivesse as habilidades exigidas pelo sistema. As informantes do Perfil A relataram que as aulas agradavam mais os meninos porque as atividades trabalhadas apareciam na rotina dos mesmos: "qualquer coisa eles fazem"; "agrada mais os meninos, porque eles jogam melhor, e as garotas não jogam bem". Outra informante relatou que agradava aos dois sexos de igual forma, se a menina não aprendia é porque não se esforçava suficientemente: "às vezes, também, depende das pessoas". Outra aluna comentou ainda que as aulas agradavam os dois sexos, simplesmente "porque os dois gostavam de participar", sem falar das diferentes formas de participação, já que algumas práticas eram mais valorizadas do que outras.

As meninas do Perfil B relataram os mesmos sentidos com exemplos diferentes. Duas comentaram que as aulas agradavam os ativos: "eu acho que agrada mais os meninos, algumas meninas, nem todas, às vezes elas (as meninas) vêm pra aula, pra ficar sentadas". Outra informante comentou que a aula agradava aos "dois

Mavimento, Porto Alegre, v.13, n. 01, p.37-56, janeiro/abril de 2007. 
sexos, se fossem todos juntos, [...] porque eles são melhor do que a gente, acho que eles tinham que maneirar um pouquinho", ou seja, mesmo agradando a todos, seria melhor que meninos e meninas estivessem juntos para aprender com as diferenças.

As meninas do Perfil C ousaram nas opiniões, com palavras que demonstraram sentimento de frustração em relação às possibilidades de participação, ou seja, não importa o sexo que se beneficie, elas não seriam privilegiadas. Duas achavam que os dois sexos eram agradados e respeitados do mesmo jeito, sem demonstrar muito interesse em dialogar sobre o assunto: "acho que os dois; os dois, né?". Uma menina disse que a aula agradava "os dois, não tem essa de ficar separando um do outro", revelando que ainda podia melhorar se meninos e meninas ficassem juntos. Com isso, melhorariam a convivência, permitindo maior conhecimento e compreensão sobre as atitudes do outro. Uma terceira informante frisou: "respeita mais os meninos", porque "eles jogam melhor". Para essas alunas, as professoras incentivam mais os meninos do que as meninas durante as atividades.

A maioria das meninas reconhecia que, se tivesse mais tempo para treinar e mais alternativas de participação, sem valorização de alguns conteúdos sobre outros, sem a cobrança exacerbada das habilidades técnicas, a aula seria mais motivante. Para elas, a oportunidade estava lançada, mas como aprender a jogar se o tempo dividido da aula era tão exíguo? Como ser reconhecida pelos colegas se eles não intercambiavam informações com as meninas? Como gostar de uma aula que valoriza a técnica, a partir de um padrão culturalmente definido pelos meninos?

\section{CONSIDERAÇÕES FINAIS}

Inicialmente, faz-se necessário apontar que, mesmo constando para a Secretaria Municipal de Educação que as aulas de educação física nas escolas eram co-educativas (meninos e meninas integrados em aulas mistas), na pesquisa de campo, verificamos que, na prática cotidiana das escolas, os professores burlam esta determinação e ora separam os meninos das meninas, ora põem todos juntos, dependendo das conveniências dos professores.

Movimento, Porto Alegre, v.13, n. 01, p.37-56, janeiro/abril de 2007. 
Isto significa que quando a escola possuía mais de um espaço destinado às aulas de educação física, os meninos ficavam em um espaço e as meninas em outro. E quando só existia um espaço para as aulas, o tempo de aula era dividido, primeiro com a ocupação de meninos e depois de meninas. Esta situação foi também detectada na pesquisa de Abreu (1990), o que nos permite inferir que estas dificuldades continuam na rotina de aulas dos professores.

Observamos que as diferenças motoras apresentadas ainda são reforçadas no âmbito das aulas mistas de educação física. Entretanto, se houver maior comprometimento dos professores de educação física a respeito do entendimento das diferenças entre os meninos durante as aulas mistas, podemos romper as barreiras que se manifestam entre os adolescentes e interferem tanto no desenvolvimento sócio-afetivo quanto na motricidade deles.

Focalizando as questões centrais da pesquisa, encontramos diferentes sentidos sobre os critérios de seleção para a participação das meninas do $4^{\circ}$ ciclo do ensino fundamental em aulas mistas de educação física, relacionados a seguir.

As alunas gostariam que fossem ministrados outros conteúdos nas aulas de educação física, e, dessa forma, terem ampliadas as suas experiências motoras e culturais. As mesmas apontam para uma participação mais cooperativa nas aulas mistas de educação física, onde fossem superadas as concepções de que elas, para os meninos, são naturalmente pouco habilidosas.

Sobre como eram vistas pelos colegas - meninos e meninas -, as adolescentes relataram os preconceitos sofridos: i) ou surpreendiam porque, mesmo sendo meninas, inacreditavelmente sabiam jogar - perfil A; ii) ou eram desvalorizadas por tentarem aprender os fundamentos e não conseguirem melhorar suas habilidades perfil B; iii) ou eram ignoradas quando não dominavam as técnicas e habilidades esportivas exigidas como necessárias para as práticas - perfil C.

Quanto às formas de participação adotadas nas aulas de educação física, as meninas demonstraram comportamentos cooperativos entre si; participavam ajudando a professora e atestavam Movimento, Porto Alegre, v.13, n. 01, p.37-56, janeiro/abril de 2007. 
que sua participação dependia da ação da mesma, que selecionava as que jogariam ou as que escolheriam os times.

As formas de seleção utilizadas para a participação nas aulas mistas revelaram uma hierarquização de critérios de seleção entre a habilidade e a amizade. As meninas menos hábeis e que não tinham uma relação de amizade com as mais hábeis tendiam à autoexclusão, enquanto as mais habilidosas eram sempre aquelas que escolhiam os times nas aulas.

Em relação às oportunidades de participação nas atividades das aulas de educação física, as meninas reconheceram que as aulas garantem as mesmas oportunidades para ambos os sexos - valorizam as habilidades técnicas esportivas, porém indicaram que estas não eram dadas ao mesmo tempo e não havia o mesmo espaço para todos, pois não jogavam em times mistos porque as professoras argumentavam que as diferenças de habilidade e interesse interferiam na aprendizagem de certas atividades pelos alunos.

A partir das falas das adolescentes, percebemos que a escola não somente acolhe as diferenças humanas e sociais como permite que surjam novas diferenças, instaurando novas demandas. Sabemos que são imensas as dificuldades de se modificar concepções e comportamentos sexistas, porém, é possível perceber não apenas a perpetuação desse movimento, como também as mudanças que vêm ocorrendo. Entretanto, é importante observar que esta temática no campo da educação física escolar, na sociedade brasileira, segue uma forte tradição cientificista, e as políticas produzidas sobre o corpo masculino e feminino, sobretudo no recorte da virada do século XIX em diante, indicam que a relação corpo, sexo e gênero, interpreta os usos sociais e políticos do modelo de dois sexos e, na maioria das vezes, realizam esta interpretação de forma sexista.

Almejando reconstruir novas relações de gênero, fundadas não somente nas diferenças, mas também nas semelhanças, buscamos a liberdade de expressão dos meninos e meninas, independentemente do sexo ou de qualquer outro tipo de discriminação. A dicotomia preconceito versus cidadania deve ser uma das questões mais inquietantes na contemporaneidade e o desafio urgente que

Movimento, Porto Alegre, v.13, n. 01, p.37-56, janeiro/abril de 2007. 
se impõe aos educadores é o de fomentar, já nos bancos escolares, uma "ética da tolerância" entre as pessoas, compatibilizando democraticamente o peso de suas diferenças corporais, políticas, religiosas, econômicas e sócio-culturais.

Female teenagers' representation of the criteria
used to define participation in co-educational
physical education classes
Abstract: This study observes that the unequal
opportunities in the routine of physical education
classes point to generic embodiments relating to
male patterns. Thus, it is relevant to investigate the
students' representation of the criteria used to select
participation in co-educational classes. By means
of ethnography, it was analyzed the discourse of 12
female teenagers in the second year of junior high
school of 4 public municipal schools in Rio de Ja-
neiro, Brazil, and 80 classes were also observed. It
was possible to verify that these criteria of selection
are defined by the ability and technique in the
students' gestures and that the teacher keeps the
gestures pertaining to male ability as a reference.
Since most girls don't match this profile, they set
themselves apart from the classes, even when the
teacher is concerned with creating equal partici-
pation opportunities.
Keywords: Adolescent. Identity gender. Physical
Education. Education Primary and Secondary.

Mavimento, Porto Alegre, v.13, n. 01, p.37-56, janeiro/abril de 2007. 


Interpretaciones de adolescentes femeninas
acerca de los criterios de selección utilizados para
la participación en clases mixtas de educación
física
Resumen: Este estudio observa que las oportuni-
dades desiguales en el cotidiano de la educación
física escolar apuntan para corporalidades
generificadas referentes a los padrones masculi-
nos. De esta forma, investigar las representaciones
de estudiantes de $7^{\circ}$ año, sobre los criterios de
selección utilizados para su participación en clases
mixtas se torna relevante. Por medio de la realiza-
ción de una etnografía se analizó la opinión de 12
adolescentes del sexo femenino, de 70 año de 4
Escuelas Públicas Municipales de Río de Janeiro,
complementándose con 80 clases observadas. Fue
posible verificar que los criterios de selección son defi-
nidos por la habilidad y la técnica en los gestos
deportivos que el profesor mantiene como referencia
de los gestos la habilidad masculina, como las niñas
en su mayoría no alcanzan este perfil, se mantienen
excluidas de las clases aún cuando el profesor tiene
la preocupación de crear oportunidades iguales de
participación.
Palabras Clave: Adolescente. Identidad de género.
Educación Física. Educación primaria y secundaria.

\section{REFERÊNCIAS}

ABREU, N. G. Meninos pra cá, meninas pra lá. 1990, 189 f. Dissertação (Mestrado) - Curso de Educação Física, Universidade Gama Filho, Rio de Janeiro, 1990.

ADELMAN, M. Mulheres atletas: re-significações da corporalidade feminina Revista Estudos Feministas, Florianópolis, v. 11, n. 2, p.445-465, jul./dez. 2003.

BOURDIEU, P. A dominação masculina. Rio de Janeiro: Bertrand Brasil, 1999.

FANTE, C. Fenômeno bullying: como prevenir a violência nas escolas e educar para paz. Campinas: Verus, 2005.

FOUCAULT, M. Vigiar e Punir. 15. ed, Petrópolis: Vozes, 1997.

GEERTZ, C. A interpretação das culturas. Rio de Janeiro: Guanabara Koogan, 1989.

GOFFMAN, E. Estigma: notas sobre a manipulação da identidade deteriorada. 4. ed. Rio de Janeiro: Zahar, 1982.

Movimento, Porto Alegre, v.13, n. 01, p.37-56, janeiro/abril de 2007 
56 Astigos Origimair Marco Antônio de Carvalho Ferretti e Jorge Dorfman Knijinik

LENSKYJ, Helen. Out of Bounds: Women, Sport and Sexuality. Toronto: The Women's Press, 1986.

LOURO, G. Gênero, sexualidade e educação: uma perspectiva pós-estruturalista. 4. ed. Petrópolis: Vozes, 2001

LOURO, G. L. Currículo, gênero e sexualidade: o normal, o diferente e o excêntrico. In: LOURO, G. L., NECKEL, J. F. ; GOELLNER, S. V. Corpo, gênero e sexualidade: um debate contemporâneo. Petrópolis: Vozes, 2003. p.41-52.

LÜDKE, M.; ANDRÉ, M. E. D. A. Pesquisa em educação: abordagens qualitativas. São Paulo: EPU, 1986.

MEYER, D.; SOARES, R. Corpo, gênero e sexualidade. Porto Alegre: Mediação, 2004.

ORLANDI, E. P. Análise de discurso: princípios e procedimentos. Campinas: Pontes, 2000.

RICHARDSON, R. J. Pesquisa social: métodos e técnicas. São Paulo: Atlas, 1989.

SARAIVA, M. C. Co-educação física e esportes: quando a diferença é mito. 2. ed. Ijuí: Ed. Unijuí, 2005.

SCOTT, J. Gênero: uma categoria útil de análise histórica. Educação \& Realidade, Porto Alegre, v. 20, n. 2, p.71-99, 1995.

Mavimento, Porto Alegre, v.13, n. 01, p.57-80, janeiro/abril de 2007. 